\title{
Cogging Torque Reduction in Permanent Magnet Machines
}

\author{
Luke Dosiek, Student Member, IEEE, and Pragasen Pillay, Fellow, IEEE
}

\begin{abstract}
This paper examines two methods-magnet shifting and optimizing the magnet pole arc-for reducing cogging torque in permanent magnet machines. The methods were applied to existing machine designs and their performance was calculated using finite-element analysis (FEA). Prototypes of the machine designs were constructed and experimental results obtained. It is shown that the FEA predicted the cogging torque to be nearly eliminated using the two methods. However, there was some residual cogging in the prototypes due to manufacturing difficulties. In both methods, the back electromotive force was improved by reducing harmonics while preserving the magnitude.
\end{abstract}

Index Terms-Brushless machines, cogging torque, finite element, permanent magnet (PM), torque ripple.

\section{INTRODUCTION}

B RUSHLESS permanent-magnet (PM) machines are becoming increasingly popular in industrial applications. They offer a highly efficient, high power-density, low size alternative to conventional machines, and as their cost continues to decrease they have the opportunity to become a dominant force in the industrial applications market [1], [2]. One major drawback to PM machines is the torque ripple that is inherent in their design. This ripple is parasitic, and can lead to mechanical vibration, acoustic noise, and problems in drive systems. Minimizing this ripple is of great importance in the design of a PM machine [3].

One of the main contributors to this torque ripple is cogging torque, which is the interaction between the PMs and the stator slots. It is caused by an uneven air-gap permeance resulting in the magnets constantly seeking a position of minimum reluctance. Several methods have been proposed to reduce cogging torque including teeth pairing, magnet shaping and sizing, adding dummy stator slots, shifting magnets, and skewing [2], [4]-[8].

This paper first examines the effects of the magnet shifting method, which involves arranging the magnets in the rotor so they are distributed in such a way as to suppress lower order

Paper IPCSD-07-041, presented at the 2006 Industry Applications Society Annual Meeting, Tampa, FL, October 8-12, and approved for publication in the IEEE TRANSACTIONS ON INDUSTRY APPLICATIONS by the Electric Machines Committee of the IEEE Industry Applications Society. Manuscript submitted for review January 10, 2007 and released for publication May 31, 2007.

L. Dosiek is with the Department of Electrical and Computer Engineering, University of Wyoming, Laramie, WY 82071 USA (e-mail: ldosiek@ uwyo.edu).

P. Pillay is with the Department of Electrical and Computer Engineering, Clarkson University, Potsdam, NY 13699-5720 USA, and also with the University of Cape Town, Rondebosch 7701, South Africa (e-mail: pillayp@ clarkson.edu).

Digital Object Identifier 10.1109/TIA.2007.908160 harmonics of the cogging torque as seen in [7]. The selection of the optimum pole arc to pole pitch ratio for the new magnet shifting configuration is considered to further reduce cogging and to compensate for the decrease in back electromotive force (EMF) caused by the shifting of the magnet. This combination of methods is examined using the finite element method and a set of prototyped motors to provide experimental results.

\section{Reducing Cogging Torque}

In its most fundamental form, cogging torque can be represented by

$$
T_{\operatorname{cog}}=-\frac{1}{2} \phi_{g}^{2} \frac{d R}{d \theta}
$$

where $\phi_{g}$ is the air-gap flux, $R$ is the air-gap reluctance, and $\theta$ is the position of the rotor [1]. This supports the idea that cogging torque is the interaction between the magnets (the source of the air-gap flux since cogging torque is considered with an unexcited stator) and the stator teeth (the source of the varying air-gap reluctance). The air-gap reluctance varies periodically, thus causing the cogging torque to be periodic [9].

Because of this periodicity, cogging torque can be expressed as a Fourier series

$$
T_{\mathrm{cog}}=\sum_{k=1}^{\infty} T_{m k} \sin (m k \theta)
$$

where $m$ is the least common multiple of the number of stator slots $\left(N_{s}\right)$ and the number of poles $\left(N_{p}\right), k$ is an integer, and $T_{m k}$ is a Fourier coefficient [2]. It is seen that the cogging torque has $m$ periods per mechanical revolution of the rotor and has a direct relationship to the number of slots and poles.

To theoretically eliminate cogging torque via machine design, one must examine the equations that define it. From the inspection of (1), it is seen that cogging torque can be eliminated by forcing either the air-gap flux, $\phi_{g}$, or the rate of change of the air-gap reluctance, $d R / d \theta$, to be zero. Making $\phi_{g}$ zero is not possible since the air-gap flux is needed for the alignment and reluctance torque components that drive the machine. Therefore, cogging torque can be canceled by forcing the air-gap reluctance to be constant with respect to rotor position. In practice, cogging torque cannot be easily eliminated, but it can be greatly reduced [1].

Examination of (2) reveals that cogging torque can be represented as a Fourier series so it is a summation of harmonic sinusoids. In traditional machines with no cogging torque reduction design techniques, the rotor magnets have an additive effect 


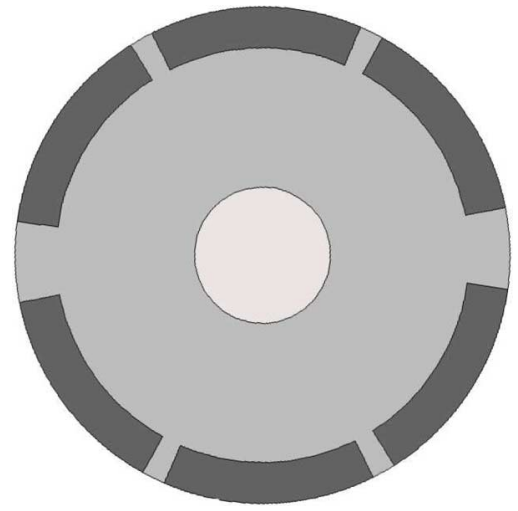

Fig. 1. Cross section of a rotor with shifted magnets.

when contributing to cogging torque because each magnet has the same relative position with respect to the stator slots [2]. The torque from each magnet is in phase with the others, and thus the harmonic components of each are added. By designing a machine in such a way that the cogging effects from the magnets are out of phase with each other, some of the harmonics seen in (2) can be eliminated, thus reducing cogging torque.

The following design technique is a combination of methods that utilize the aforementioned cogging torque reduction theories. It should be noted that although these techniques are successful in reducing the undesired cogging torque, when used alone, they also reduce the desired mutual torque. Along with the higher manufacturing costs associated with the generally more complex machine designs, these are the two main tradeoffs in reducing cogging torque [1].

\section{A. Optimal Pole Arc}

It is a well-established fact that the magnet pole arc can have a large effect on the magnitude of the cogging torque [1], [3]-[6], [8]. There exists an optimum value for the pole arc that minimizes cogging, which can be found using

$$
\alpha_{m}=\frac{n+\nu}{N_{s m}}<1, \quad 0<\nu<1
$$

where $\alpha_{m}$ is the ratio of pole arc to pole pitch, $n$ is an integer, $N_{s m}$ is the number of slots per pole, and $\nu$ is the parameter that is varied to minimize cogging [1]. For a given value of $n$, there exist $i$ values of $\nu$ that will minimize the $i$ th harmonic of the cogging torque. Finding the proper values of $\nu$ is not trivial and requires the use of finite-element analysis (FEA) [5].

\section{B. Magnet Shifting}

In traditional machines, the cogging torque contributions from each magnet are in phase and thus add to produce the full cogging effect. To avoid this additive effect, the magnets can be shifted relative to each other to place each magnet's cogging torque out of phase with the others [7]. One such configuration is shown in Fig. 1. This approach varies slightly depending on whether the number of slots per pole is an integer, so each configuration will be addressed separately [10], [11].

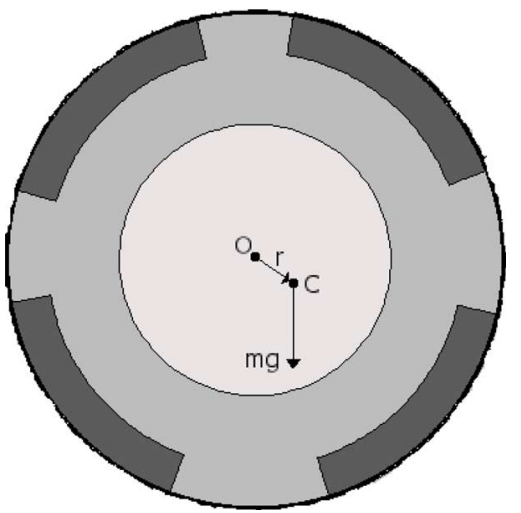

Fig. 2. Diagram of a rotor with shifted magnets showing an exaggerated offset center of mass.

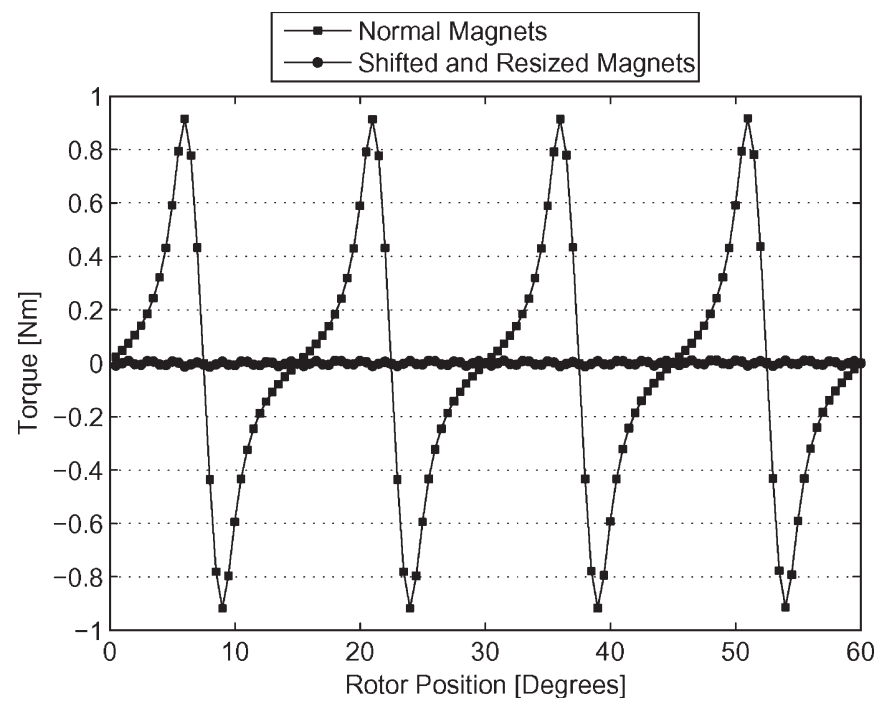

Fig. 3. Cogging torque of the four-pole machines.

1) Integer Number of Slots per Pole: In machines with an integer number of slots per pole, each pole sees a whole number multiple of stator teeth so the cogging effects of each magnet are in phase and added [1]. The cogging torque contribution of each magnet is

$$
T_{\operatorname{cog}_{p}}=\sum_{k=1}^{\infty} T_{p_{N_{s} k}} \sin \left(N_{s} k \theta\right)
$$

where $T_{p_{N_{s}}}$ is a per magnet coefficient. The total cogging torque for a machine with an integer number of slots per pole becomes

$$
T_{\operatorname{cog}}=N_{p} \sum_{k=1}^{\infty} T_{p_{N_{s} k}} \sin \left(N_{s} k \theta\right)
$$

which is equivalent to a rewritten version of (2)

$$
T_{\operatorname{cog}}=\sum_{k=1}^{\infty} T_{N_{s} k} \sin \left(N_{s} k \theta\right) .
$$

Note that the fundamental frequency of (6) is $N_{s}$ times one mechanical rotation, meaning that for machines with an integer number of slots per pole, the least common multiple of the 


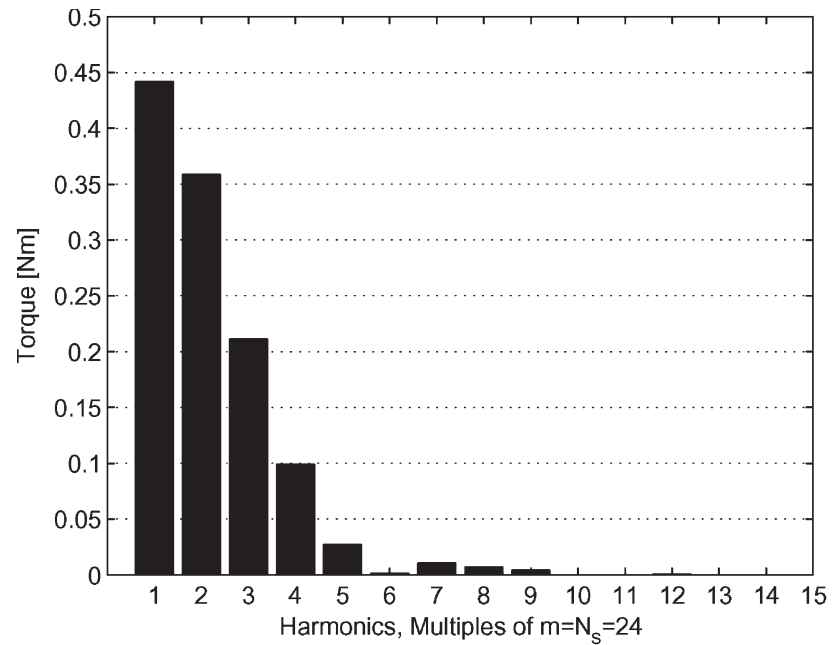

(a)

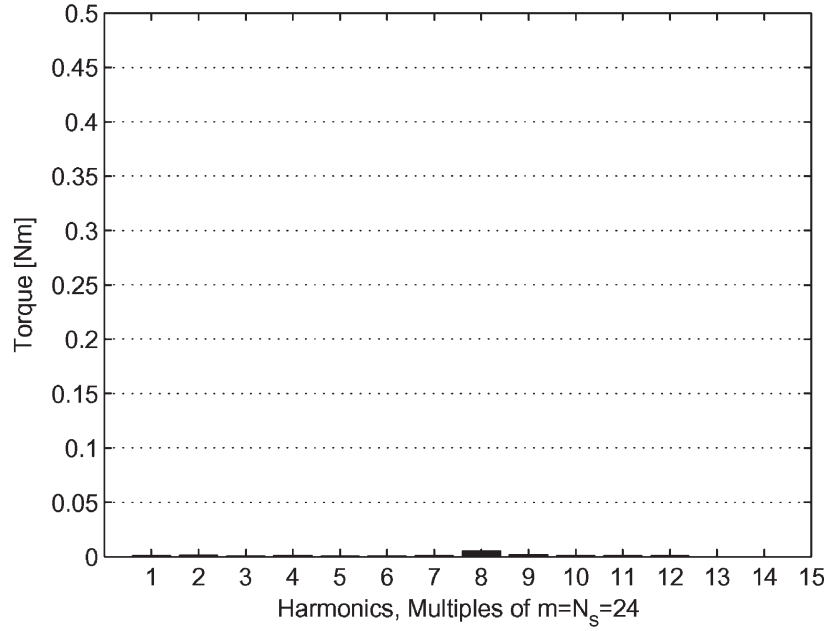

(b)

Fig. 4. Harmonic content of the cogging torque for the four-pole machines. (a) Normal magnets. (b) Shifted and resized magnets.

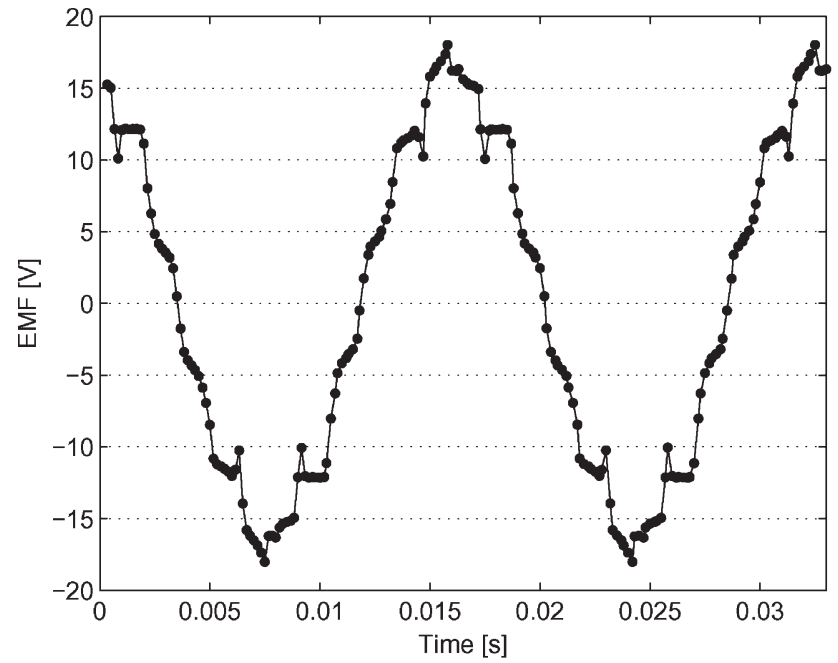

(a)

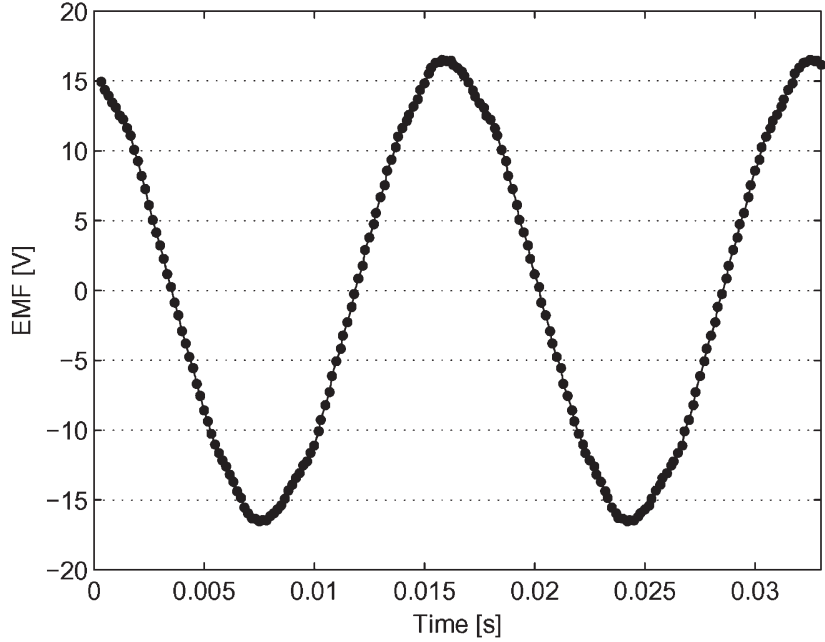

(b)

Fig. 5. Back EMF of the four-pole machines. (a) Normal magnets. (b) Shifted and resized magnets.

number slots and number of poles, $m$, is simply equal to the number of slots, $N_{s}$.

Because each magnet is in phase with the rest, each is considered for shifting relative to the others. The total cogging torque in the machine is the sum of the phase shifted contributions from each magnet

$$
T_{\operatorname{cog}}=\sum_{h=0}^{N_{p}-1} \sum_{k=1}^{\infty} T_{p_{N_{s}} k} \sin \left(N_{s} k\left(\theta-h \theta_{\circ}\right)\right)
$$

where $\theta_{\circ}$ is the angle that each magnet is shifted relative to the others, chosen specifically to have a canceling effect on the harmonics of the cogging torque. For the highest harmonic cancellation, $\theta_{\circ}$ should be

$$
\theta_{\circ}=\frac{2 \pi}{N_{s} N_{p}}
$$

resulting in the net cogging torque being reduced to

$$
T_{\mathrm{cog}}=\sum_{k=1}^{\infty} T_{N_{s} N_{p} k} \sin \left(N_{s} N_{p} k \theta\right) .
$$

All of the harmonics except multiples of the $N_{p}^{t h}$ are canceled, thus reducing the cogging torque.

2) Fractional Number of Slots per Pole: By using a fractional number of slots per pole, each magnet sees a fractional number of slots and therefore the cogging torque contribution from the magnets are out of phase with each other, thus reducing the overall cogging torque [1]. The least common multiple of the number of slots and number of poles, and thus the fundamental frequency of the overall cogging torque, is an integer multiple of the number of slots

$$
m=\gamma N_{s}
$$


The integer multiple $\gamma$ determines how many groups of magnets are out of phase with each other. Equation (5) is rewritten to account for the phase shift

$$
T_{\operatorname{cog}}=\frac{N_{p}}{\gamma} \sum_{h=0}^{\gamma-1} \sum_{k=1}^{\infty} T_{p_{N_{s} k}} \sin \left(N_{s} k\left(\theta-\frac{2 \pi h}{N_{s} \gamma}\right)\right) .
$$

The phase shifting cancels every harmonic except multiples of $\gamma^{\text {th }}$ and (11) becomes

$$
T_{\mathrm{cog}}=N_{p} \sum_{k=1}^{\infty} T_{p_{\gamma N_{s} k}} \sin \left(\gamma N_{s} k \theta\right)
$$

An examination of (6), (10), and (12) reveals that (12) reduces to (2), thus proving that the fundamental frequency of the cogging torque is $m$ regardless of the number of slots per pole.

In machines with a fractional number of slots per pole, because there are $\gamma$ groups of magnets that are already out of phase with each other, each group needs to be considered separately, i.e., the magnets are shifted relative to the others in their group only. The cogging torque contributed from each group is

$$
T_{\operatorname{cog}_{g}}=\sum_{h=0}^{\frac{N_{p}}{\gamma}-1} \sum_{k=1}^{\infty} T_{p_{N_{s}} k} \sin \left(N_{s} k\left(\theta-h \theta_{\circ}\right)\right)
$$

where for maximum harmonic cancellation

$$
\theta_{\circ}=\frac{2 \pi \gamma}{N_{s} N_{p}} .
$$

The resulting cogging torque per group of magnets simplifies to

$$
T_{\operatorname{cog}_{g}}=\frac{N_{p}}{\gamma} \sum_{k=1}^{\infty} T_{p_{N_{s}} \frac{N_{p}}{\gamma} k} \sin \left(N_{s} \frac{N_{p}}{\gamma} k \theta\right) .
$$

Equation (11) can be applied to the cogging torques from each magnet group yielding the total machine cogging torque

$$
T_{\operatorname{cog}}=\frac{N_{p}}{\gamma} \sum_{h=0}^{\gamma-1} \sum_{k=1}^{\infty} T_{p_{N_{s} \frac{N_{p}}{\gamma} k}} \sin \left(N_{s} \frac{N_{p}}{\gamma} k\left(\theta-\frac{2 \pi h}{N_{s} \gamma}\right)\right)
$$

which reduces to

$$
T_{\operatorname{cog}}=N_{p} \sum_{k=1}^{\infty} T_{p_{N_{s} N_{p} k}} \sin \left(N_{s} N_{p} k \theta\right) .
$$

Equivalent to (9), this shows that regardless of the number of slots per pole, the fundamental frequency of the resulting cogging torque is $N_{s} N_{p}$ times per mechanical revolution for a machine with properly shifted magnets.

For both of the above cases, there exist many different combinations of magnet shifting that mathematically reduce cogging torque because the magnets are shifted relative to each other, not a fixed point of reference. However, some of these combinations produce a more asymmetrical rotor than others [2]. The more asymmetrical the rotor, the more the center of mass deviates from the axis of rotation, thus introducing

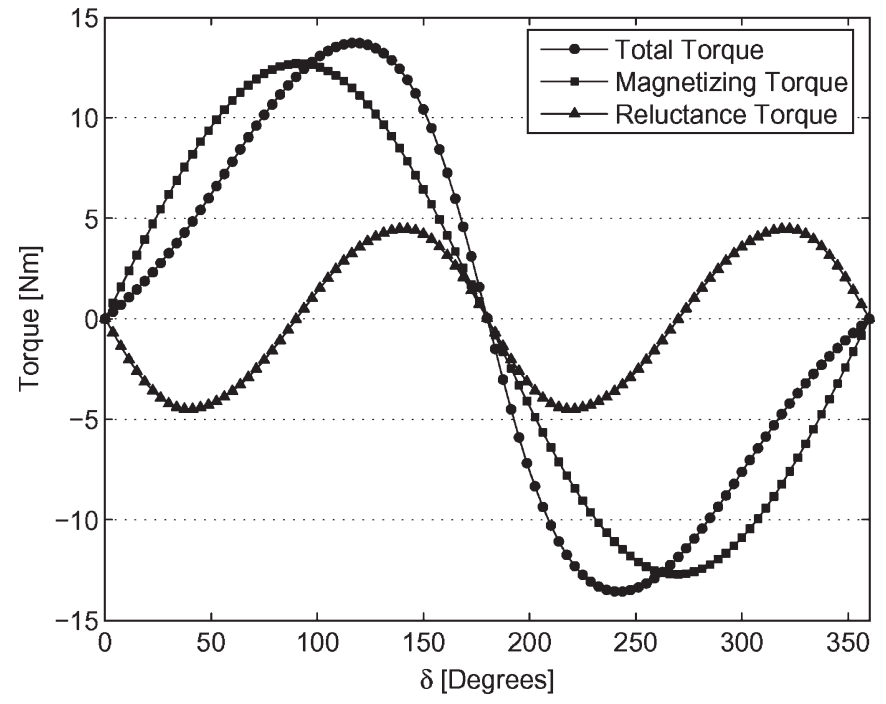

Fig. 6. Torque versus stator current angle curve showing slight asymmetry.

mechanical vibration. Depending on the level of vibration, it could be mechanically corrected. This unbalance is undesired and should be minimized through the selection of the best combination of magnet shifts. In the special case of a fractional number of slots per pole with an odd number of magnets per group, rotor symmetry can be preserved with magnet shifting.

\section{Combination of Methods}

This paper examines the combination of the above two methods. This requires that the magnets first be shifted so that the cogging torque is reduced and the fundamental frequency is increased to $N_{s} N_{p}$. A magnet arc should then be chosen that minimizes this harmonic, resulting in the lowest harmonic of the final design's cogging torque being $2 N_{s} N_{p}$. The new magnet arc should be chosen to be slightly larger than the original design's to compensate for the reduction in back EMF created by the magnet shifting. This theoretically reduces cogging torque while preserving the machine's rated performance.

\section{NUMERICAL ANALYSIS}

The numerical results were calculated using the finite element method with Magsoft's Flux package. The cogging torque was calculated with the Maxwell stress method [12]. The harmonic spectra of the cogging torque were calculated using Fourier sine series.

The methods discussed were applied to a 24-slot 4-pole motor design with $120^{\circ}$ magnet arcs. Because the machine had an integer number of slots per pole, (8) was used to establish that each magnet needed to be shifted $3.75^{\circ}$ relative to the others. To achieve this, the first magnet was shifted $5.625^{\circ}$, the second $-1.875^{\circ}$, the third $-5.625^{\circ}$, and the fourth $1.875^{\circ}$ from their original positions. Since this configuration would result in the cogging torque having a fundamental of 96 periods per mechanical revolution, a magnet arc of $124.8^{\circ}$ was found to minimize the new fundamental while increasing the back EMF due to its slight increase in size. 


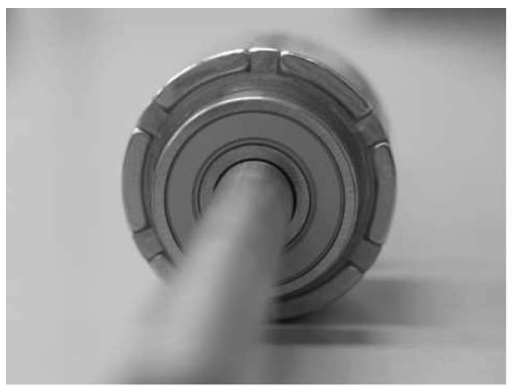

(a)

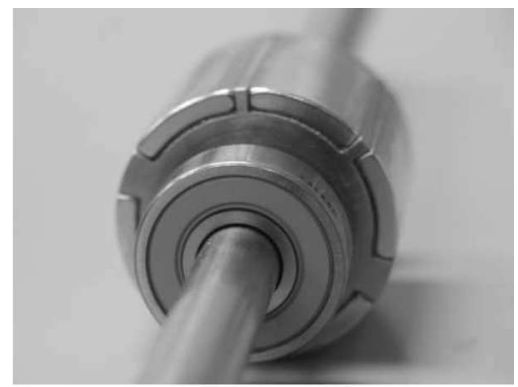

(b)

Fig. 7. Rotors used in experimental analysis. (a) Normal magnets. (b) Shifted and resized magnets.

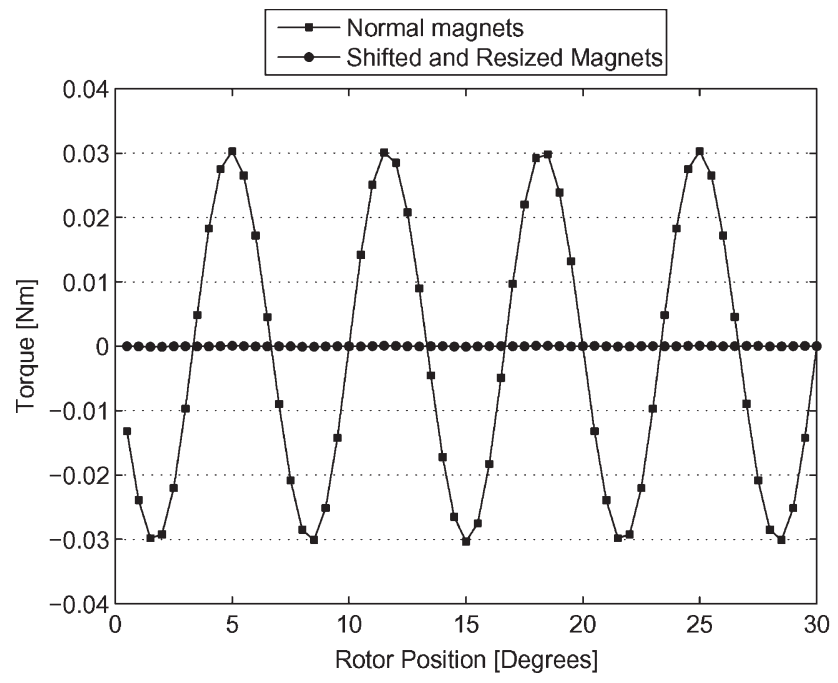

(a)

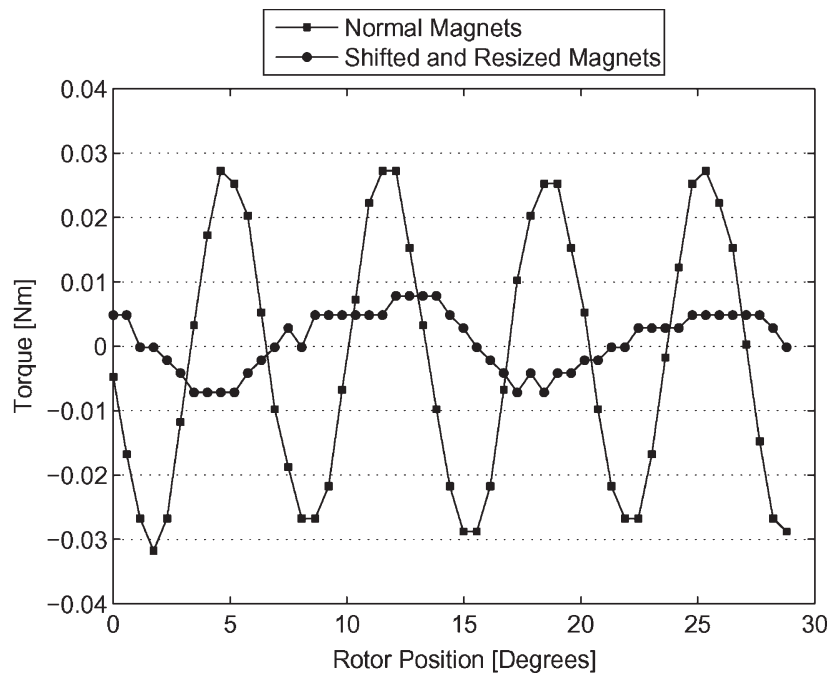

(b)

Fig. 8. Cogging torque of the six-pole machines. (a) Finite-element results. (b) Experimental results.

Shown in Fig. 2, the resultant design produced an asymmetric rotor with a center of mass that was offset from the axis of rotation. Because the densities of the rotor steel and magnets were very similar (7.7 and $7.5 \mathrm{~kg} / \mathrm{dm}^{3}$, respectively), the moment created by the asymmetry was only $0.001 \mathrm{~N} \cdot \mathrm{m}$, a mere $4 \%$ of the design's $0.023 \mathrm{~N} \cdot \mathrm{m}$ cogging torque ripple.

Fig. 3 shows the cogging torque results. The original design was found to have a peak-to-peak cogging torque of $1.83 \mathrm{~N} \cdot \mathrm{m}$. The new design resulted in a peak-to-peak cogging torque of $0.023 \mathrm{~N} \cdot \mathrm{m}$, which is a $99 \%$ reduction from the original design. In Fig. 4, the harmonics of the cogging torque can be seen. The original machine displayed noticeable energy in the first nine harmonics, with the majority located in the first four. The redesigned machine showed the canceling effects of the shifted magnets combined with the proper magnet pole arc. The only harmonic with any significant energy was the eighth, supporting the proposed theory.

\section{A. Back EMF}

Fig. 5 shows the back EMF of both machine designs. The results showed that the redesigned machine lacked the harmonics found in the original machine. This was due to the fact that back EMF is directly proportional to the rate of change of the flux through each phase, which is also proportional to developed torque [2]. Since the new design reduced much of the torque ripple, it reduced the harmonics in the EMF, lowering the total harmonic distortion (THD) from $6.02 \%$ to $1.32 \%$. The magnitude of the voltage was unchanged by the magnet shifting and resizing, with each producing $11.44 \mathrm{~V}_{r m s}$.

\section{B. Operation Under Vector Control}

One potentially adverse effect of the magnet shifting observed was that the maximum available torque in the motoring mode of operation was slightly different from that of the braking mode. This was due to the asymmetric air-gap reluctance created by the shifted magnets. Shown in Fig. 6, the reluctance torque (as a function of the stator current phase angle), had its maximum and minimum values shifted by $5.625^{\circ}$, the largest angle the magnets were shifted. For the four-pole machine examined, the unbalance in total torque was very small, $0.1 \mathrm{~N} \cdot \mathrm{m}$, but is nonetheless something to be considered.

\section{EXPERIMENTAL ANALYSIS}

For the experimental analysis, a 27-slot six-pole motor was used. Because it utilized a fractional number of slots per pole, the fundamental frequency of the cogging torque of the normal machine was 54 times per mechanical revolution, or twice 


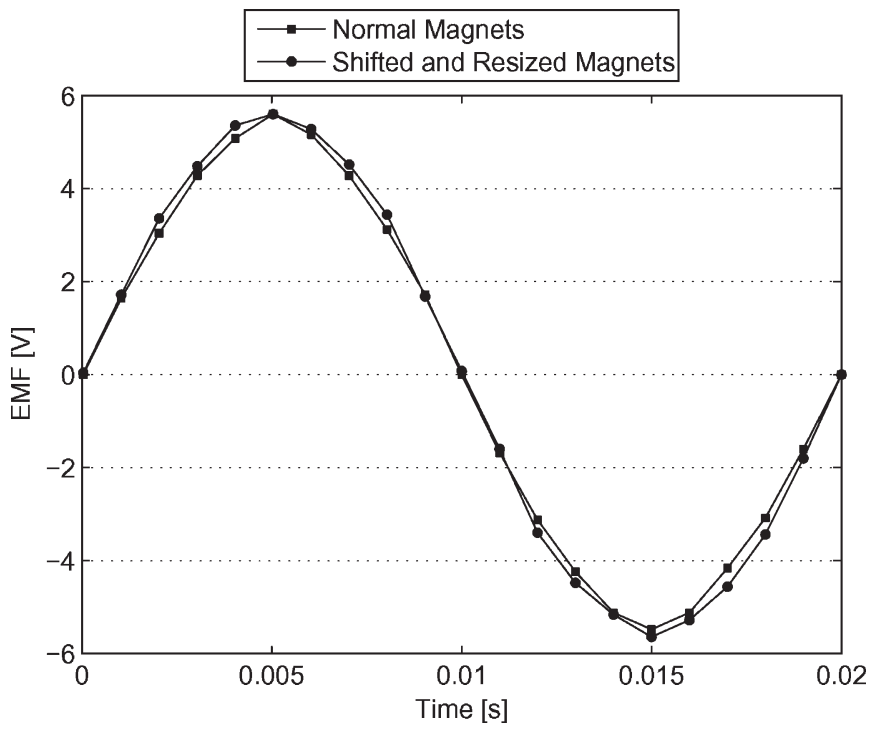

Fig. 9. Measured back EMF of the six-pole machines.

the number of slots resulting in a $\gamma$ of 2 . This resulted in 2 groups of 3 magnets each that needed to be addressed for magnet shifting. According to (14), the magnets needed to be shifted $4.44^{\circ}$ relative to the other magnets in their group. It was found that by keeping one magnet in each group in its original position and then shifting one magnet clockwise and the other counterclockwise $4.44^{\circ}$, a rotor could be created with no offset in the center of mass, as shown in Fig. 1. The magnet arcs were increased from $144^{\circ}$ to $150^{\circ}$ to regulate the back EMF and to minimize the lowest harmonic of the cogging torque of the machine after the magnets were shifted. Two rotors were prototyped, one with normal magnets and one with shifted and resized magnets, as shown in Fig. 7.

The cogging torque as calculated with FEA was $0.061 \mathrm{~N} \cdot \mathrm{m}$ peak-to-peak for the machine with the normal magnets and $0.00018 \mathrm{~N} \cdot \mathrm{m}$ peak-to-peak for the machine with the shifted and resized magnets, predicting a $99.7 \%$ reduction. In reality, however, the reduction was not as dramatic.

Shown in Fig. 8, the measured cogging torque of the machine with the normal magnets of $0.060 \mathrm{~N} \cdot \mathrm{m}$ was in good agreement with the predicted results. For the machine with the shifted magnets, the measured cogging torque of $0.019 \mathrm{~N} \cdot \mathrm{m}$ was considerably larger than the predicted value. Due to a slight eccentricity on the rotor surface because of manufacturing, a component of cogging torque arose that had one period per stator tooth. A relatively small motor, the tolerances required by the design were too high for the available machine shop. Despite this, the design still managed to reduce the cogging by $68.3 \%$. The measured back EMF of the two designs showed that the magnitude was slightly increased from $3.8 \mathrm{~V}_{r m s}$ to $3.9 \mathrm{~V}_{r m s}$, while the shifted magnet design reduced the THD from $2.11 \%$ to $1.38 \%$ (Fig. 9).

\section{CONClusion}

It was shown that through a combination of the methods of magnet shifting and optimizing the magnet arc, the cogging torque could theoretically be nearly eliminated without com- promising the back EMF in machines with either an integer or fractional number of slots per pole. In practice, however, the method when applied to particularly small motors could demand high machining tolerances that could result in slight manufacturing defects giving rise to small, yet noticeable cogging torques.

\section{REFERENCES}

[1] D. Hanselman, Brushless Permanent-Magnet Motor Design. New York: McGraw-Hill, 1994.

[2] C. Bretón, J. Bartolomé, J. A. Benito, G. Tassinario, I. Flotats, C. W. Lu, and B. J. Chalmers, "Influence of machine symmetry on reduction of cogging torque in permanent magnet brushless motors," IEEE Trans. Magn., vol. 36, no. 5, pp. 3819-3823, Sep. 2000.

[3] Z. Q. Zhu and D. Howe, "Influence of design parameters on cogging torque in permanent magnet machines," IEEE Trans. Energy Convers., vol. 15 , no. 4, pp. 407-412, Dec. 2000

[4] S.-M. Hwang, J.-B. Eom, Y.-H. Jung, D.-W. Lee, and B.-S. Kang, "Various design techniques to reduce cogging torque by controlling energy variation in permanent magnet motors," IEEE Trans. Magn., vol. 37, no. 4, pp. 2806-2809, Jul. 2001.

[5] Z. Q. Zhu, S. Ruangsinchaiwanich, N. Schofield, and D. Howe, "Reduction of cogging torque in interior magnet brushless machines," IEEE Trans. Magn., vol. 39, no. 5, pp. 3238-3240, Sep. 2003.

[6] T. Ishikawa, "A method of reducing ripple torque in permanent magnet motors without skewing," IEEE Trans. Magn., vol. 29, no. 2, pp. 20282031, Mar. 1993.

[7] N. Bianchi and S. Bolognani, "Design techniques for reducing the cogging torque in surface-mounted PM motors," IEEE Trans. Ind. Appl., vol. 38, no. 5, pp. 1259-1265, Sep./Oct. 2002.

[8] T. Li and G. Slemon, "Reduction of cogging torque in permanent magnet motors," IEEE Trans. Magn., vol. 24, no. 6, pp. 2901-2903, Nov. 1988.

[9] J. F. Gieras, "Analytical approach to cogging torque calculation of PM brushless motors," IEEE Trans. Ind. Appl., vol. 40, no. 5, pp. 1310-1316, Sep./Oct. 2004.

[10] Z. Q. Zhu, S. Ruangsinchaiwanich, Y. Chen, and D. Howe, "Evaluation of superposition technique for calculating cogging torque in permanent magnet brushless machines," IEEE Trans. Magn., vol. 42, no. 5, pp. $1597-$ 1603, May 2006.

[11] Z. Q. Zhu, S. Ruangsinchaiwanich, and D. Howe, "Synthesis of cogging torque waveform from analysis of a single stator slot," in Proc. IEEE IEMDC, San Antonio, TX, Jun. 2005, pp. 125-130.

[12] FLUX 9.10 User's Guide, Cedrat, Meylan, France, Mar. 2005.

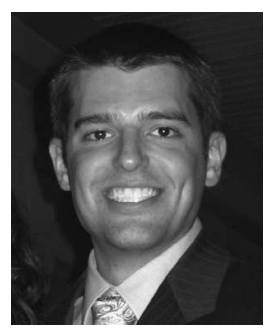

Luke Dosiek (S'06) was born in Dhahran, Saudi Arabia, in 1981. He received the B.S. and M.S. degrees in electrical engineering from Clarkson University, Potsdam, NY, in 2004 and 2006, respectively. $\mathrm{He}$ is currently working toward the Ph.D. degree in electrical engineering at the University of Wyoming, Laramie.

He visited the University of Cape Town, Cape Town, South Africa, as a Research Assistant from May to August 2004. He has interned at Bombardier Transportation, Plattsburgh, NY, and Delphi Steering, Saginaw, MI. His research interests include electric machines and drives, power system stability, signal processing, and engineering education.

Mr. Dosiek is a member of the IEEE Education, IEEE Industry Applications, IEEE Magnetics, and IEEE Power Engineering Societies. 


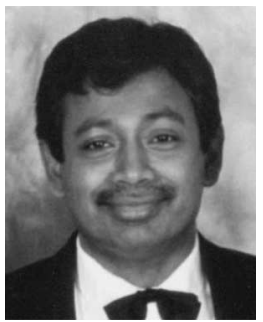

Pragasen Pillay (S'84-M'87-SM'92-F'05) received the B.S. and M.S. degrees in electrical engineering from the University of KwaZulu-Natal, KwaZulu-Natal, South Africa, in 1981 and 1983, respectively, and the Ph.D. degree in electrical engineering from Virginia Polytechnic Institute and State University, Blacksburg, in 1987, while funded by a Fulbright Scholarship.

From January 1988 to August 1990, he was with the University of Newcastle upon Tyne, U.K. From August 1990 to August 1995, he was with the University of New Orleans, New Orleans, LA. Currently, he is with Clarkson University, Potsdam, NY, where he is a Professor with the Department of Electrical and Computer Engineering and holds the Jean Newell Distinguished Professorship in Engineering. He is also an Adjunct Professor with the University of Cape Town, Cape Town, South Africa. His research and teaching interests are in modeling, design, and control of electric motors and drives for industrial and alternate energy applications.

Dr. Pillay is a member of the IEEE Power Engineering, IEEE Industry Applications, IEEE Industrial Electronics, and IEEE Power Electronics Societies. He is a member of the IEEE Industry Applications Society (IAS) Electric Machines Committee, Past Chairman of the IEEE IAS Industrial Drives Committee, and Past-Chairman of the IEEE Power Engineering Society Induction Machinery Sub-Committee. He currently chairs the Awards Committee of the IEEE IAS Industrial Power Conversion Department. He is a Fellow of the Institution of Electrical Engineers, U.K., and a Chartered Electrical Engineer. He is also a member of the Academy of Science of South Africa. He has organized and taught short courses on electric drives at the Annual Meeting of the IAS. 